\title{
RESPOSTA DE CULTIVARES DE PIMENTA-DO-REINO AOS NUTRIENTES NPK EM UM LATOSSOLO AMARELO DA AMAZÔNIA ORIENTAL
}

\author{
Carlos Alberto Costa Veloso1*; Eduardo Jorge Maklouf Carvalho; Eurípedes Malavolta²; Takashi \\ Muraoka² \\ ${ }^{1}$ Embrapa Amazônia Oriental, C.P. 48 - CEP: 66095-100 - Belém, PA. \\ ${ }^{2}$ USP/CENA, C.P. 96 - CEP: 13400-970 - Piracicaba, SP. \\ *Autor correspondente<veloso@cpatu.embrapa.br>
}

\begin{abstract}
RESUMO: O presente trabalho foi desenvolvido, com o objetivo de estabelecer curvas de resposta da pimenteirado-reino a nitrogênio, fósforo e potássio, num Latossolo Amarelo distrófico (Oxisol), no município de Senador José Porfírio, $\mathrm{km} 35$ da rodovia Transamazônica. As doses de nitrogênio, aplicadas manualmente a cada ano foram: $\left(0 ; 40 ; 80 ; 120\right.$ e $160 \mathrm{~kg} \mathrm{ha}^{-1}$ de N) na forma de uréia, cinco doses de fósforo $(0 ; 30 ; 60 ; 90$ e $\left.120 \mathrm{~kg} \mathrm{ha}^{-1} \mathrm{P}_{2} \mathrm{O}_{5}\right)$ na forma de superfosfato triplo e cinco doses de potássio $\left(0 ; 30 ; 60 ; 90\right.$ e $\left.120 \mathrm{~kg} \mathrm{ha}^{-1} \mathrm{~K}_{2} \mathrm{O}\right)$ na forma de KCl. Utilizou-se o delineamento em blocos ao acaso, com três repetições, sendo os tratamentos dispostos em esquema fatorial incompleto. O espaçamento foi de 3,0 m entre linhas e 2,5 m entre plantas, com seis plantas úteis por parcela. Os resultados evidenciaram resposta positiva de nitrogênio com relação a produção de grãos de pimenta do reino com a aplicação de 72 e $78 \mathrm{~kg} \mathrm{ha}^{-1}$ de N, para as cultivares Cingapura e Bragantina, respectivamente. Somente a cultivar Guajarina, respondeu à aplicação de fósforo. Doses crescentes de $\mathrm{K}_{2} \mathrm{O}$, reduziu os teores de potássio presentes no tecido foliar das pimenteiras. A adição de potássio favoreceu o aumento da produção de grãos com a aplicação de 42, 13 e $22 \mathrm{~kg} \mathrm{ha}^{-1}$ de $\mathrm{K}_{2} \mathrm{O}$, para as cultivares Cingapura, Bragantina e Guajarina, respectivamente.
\end{abstract}

Palavras-chave: Piper nigrum, adubação, nitrogênio, fósforo, potássio

\section{RESPONSE OF NPK FERTILIZATION BY BLACK PEPPER CULTIVARS IN AN EASTERN AMAZONIAN YELLOW LATOSOL}

\begin{abstract}
The present work was developed with the objective of establishing response curves of black pepper to nitrogen, phosphorus and potassium in an Oxisol (Yellow Latosol, dystrophic) in Senador José Porfírio County, km 35 of the Transamazonian road, in Brazil. The levels of nitrogen, applied manually every year were $\left(0 ; 40 ; 80 ; 120\right.$ and $\left.160 \mathrm{~kg} \mathrm{ha}^{-1} \mathrm{~N}\right)$ in the urea form, five phosphorus levels $(0 ; 30 ; 60 ; 90$ and $120 \mathrm{~kg}$ $\left.\mathrm{ha}^{-1} \mathrm{P}_{2} \mathrm{O}_{5}\right)$ in the form of triple superphosphate and five potassium levels $\left(0 ; 30 ; 60 ; 90\right.$ and $\left.120 \mathrm{~kg} \mathrm{ha}^{-1} \mathrm{~K}_{2} \mathrm{O}\right)$ in the form of potassium chloride. The experimental design consisted of blocks with three replicates, being the treatments disposed as an incomplete factorial. The spacing was of $3.0 \mathrm{~m}$ between lines and $2.5 \mathrm{~m}$ between plants with six useful plants per plot. The results evidenced positive response of nitrogen in relation to black pepper grain yield with the application of 72 and $78 \mathrm{~kg} \mathrm{ha}^{-1}$ of $\mathrm{N}$, for cultivars Cingapura and Bragantina, respectively. Only cultivar Guajarina responded to the phosphorus application. Growing levels of $\mathrm{K}_{2} \mathrm{O}$, reduced the present potassium content in the foliar tissue of the peppers. The potassium addition favored the increase of the production of grains with the application of 42,13 and $22 \mathrm{~kg} \mathrm{ha}^{-1}$ of $\mathrm{K}_{2} \mathrm{O}$, for the Cingapura, Bragantina and Guajarina cultivars, respectively.
\end{abstract}

Key words: Piper nigrum, fertilization, nitrogen, phosphorus, potassium

\section{INTRODUÇÃO}

A produção brasileira de pimenta-do-reino está concentrada no Estado do Pará, e a safra de 1995, obtida em 15.792 ha, foi de 27.780 toneladas, com um rendimento médio de $1.759 \mathrm{~kg} \mathrm{ha}^{-1}$, equivalente a $85 \%$ da produção nacional (Anuário, 1997). No Estado do Pará, essa cultura tem sido cultivada principalmente em solos lixiviados, com baixa fertilidade natural e elevada acidez, limitando o desenvolvimento das plantas, o que torna indispensável o uso de fertilizantes (Falesi, 1972).

$\mathrm{Na}$ literatura disponível sobre pimenta do reino, tem se verificado que os estudos executados nos principais países produtores dessa espécie mostram, de forma bem consistente, que a exigência de nutrientes pela pimenteira segue a seguinte ordem decrescente: $\mathrm{N} \mathrm{e} \mathrm{K}>\mathrm{Ca}>\mathrm{Mg}>$ $\mathrm{P}(\mathrm{Sim}, 1971)$.

Waard (1964) estimou em Sarawak, Malásia que a exigência nutricional anual da pimenteira expressa em kg ha-1 foi de 252; 13,6;186; 13,2 e 45,6 para nitrogênio, fósforo, potássio, magnésio e cálcio, respectivamente.

No Brasil, Kato (1978) estimou que as necessidades para manutenção e produção da planta adulta de pimenteira foram de $90 \mathrm{~g}$ de $\mathrm{N}, 10 \mathrm{~g}$ de $\mathrm{P}, 120$ $\mathrm{g}$ de K, $80 \mathrm{~g}$ de Ca, e $11 \mathrm{~g}$ de Mg. Segundo Sim (1971), a 
pimenteira retira grandes quantidades de nutrientes do solo, principalmente nitrogênio e potássio. As quantidades totais de macronutrientes retirados anualmente por hectare, segundo esse pesquisador, foram de $233 \mathrm{~kg}$ de $\mathrm{N}, 172 \mathrm{~kg}$ de $\mathrm{K}, 75 \mathrm{~kg}$ de $\mathrm{Ca}, 17 \mathrm{~kg}$ de P e $18 \mathrm{~kg}$ de $\mathrm{Mg}$.

Waard (1980), estabeleceu que para cada quilo de pimenta produzida são extraídos do solo $32 \mathrm{~g} \mathrm{~N}, 5 \mathrm{~g} \mathrm{P}$, $28 \mathrm{~g} \mathrm{~K}, 8 \mathrm{~g} \mathrm{Ca}$ e $3 \mathrm{~g} \mathrm{Mg}$, sendo necessários para 0 desenvolvimento da planta $106 \mathrm{~g} \mathrm{~N}, 8 \mathrm{~g} \mathrm{P}, 84 \mathrm{~g} \mathrm{~K}, 36 \mathrm{~g}$ $\mathrm{Ca}$ e $11 \mathrm{~g}$ de $\mathrm{Mg}$.

Maistre (1969), relata que a pimenteira exporta através da produção de $1 \mathrm{~kg}$ de pimenta beneficiada, 0 equivalente a $39 \mathrm{~g}$ de N, $4 \mathrm{~g}$ de $\mathrm{P}$ e $17 \mathrm{~g}$ de $\mathrm{K}$.

Chiba, citado por Moraes (1968), constatou uma grande exportação de magnésio na colheita dos frutos e encontrou um teor de $3 \mathrm{~g} \mathrm{~kg}^{-1}$ de $\mathrm{Mg}$ nos mesmos e $4,1 \mathrm{~g} \mathrm{~kg}^{-1}$ nas folhas. Em um pimental com uma produção média de $4 \mathrm{~kg}$ de pimenta/planta o que corresponde a $2544 \mathrm{~g}$ de pimenta preta, a exportação para a planta seria de $1,7 \mathrm{~g}$ de $\mathrm{Mg}$, para um conteúdo estimado nas folhas de $14 \mathrm{~g}$.

No Estado do Pará, Chiba \& Terada (1976), determinaram a marcha de absorção de vários nutrientes nessa cultura em condições de campo, concluindo que o nitrogênio foi absorvido em pequena quantidade pelas pimenteiras jovens, aumentando com a estabilização do crescimento. O potássio e o nitrogênio foram os nutrientes mais exigidos, seguindo-se o fósforo, cálcio e, por último, o magnésio.

Os resultados de pesquisas com adubação e nutrição nessa cultura, a partir do primeiro ano de cultivo e até a fase produtiva, não tem mostrado resposta e efeito interativo dos nutrientes nitrogênio, fósforo e potássio (Veloso et al., 1995).

Em função do exposto, o objetivo deste trabalho foi estabelecer curvas de resposta da pimenteira-do-reino a nitrogênio, fósforo e potássio, com as cultivares Bragantina, Cingapura e Guajarina, num Latossolo Amarelo da rodovia Transamazônica.

\section{MATERIAL E MÉTODOS}

O experimento foi conduzido no campo experimental da Embrapa Amazônia Oriental no período compreendido entre fevereiro de 1985 e julho de 1988, no município de Senador José Porfírio, km 35 da rodovia Transamazônica trecho Altamira/Marabá, em solo classificado como Latossolo Amarelo distrófico (Oxisol), textura franco-argilo-arenosa, cujas características químicas e físicas são apresentadas na TABELA 1. O clima do município, de acordo com a classificação de Koppen é do tipo Aw. A pluviosidade anual é de $1680 \mathrm{~mm}$, temperatura média anual é $26,0{ }^{\circ} \mathrm{C}$ e a umidade relativa média de $82 \%$.

Utilizou-se o delineamento em blocos ao acaso, com três repetições, sendo os tratamentos dispostos em esquema do tipo central composto não rotável (Cochran \& Cox., 1957). O espaçamento foi mantido em 3,0 m entre linhas e 2,5 m entre plantas, com seis plantas úteis por parcela. Os tratamentos no primeiro ano, corresponderam a cinco doses de nitrogênio $\left(0 ; 20 ; 40 ; 60\right.$ e $80 \mathrm{~kg} \mathrm{ha}^{-1}$ de N) na forma de uréia, cinco doses de fósforo $(0 ; 15 ; 30$; 45 e $60 \mathrm{~kg} \mathrm{ha}^{-1}$ de $\mathrm{P}_{2} \mathrm{O}_{5}$ ) na forma de superfosfato triplo e cinco doses de potássio $\left(0 ; 15 ; 30 ; 45\right.$ e $60 \mathrm{~kg} \mathrm{ha}^{-1}$ de $\left.\mathrm{K}_{2} \mathrm{O}\right)$ na forma de cloreto de potássio. No segundo ano agrícola elevou-se as doses de $\mathrm{N}, \mathrm{P}_{2} \mathrm{O}_{5}$ e $\mathrm{K}_{2} \mathrm{O}$ em $100 \%$. O superfosfato triplo foi aplicado todo de uma só vez e os demais fertilizantes foram aplicados parceladamente de três vezes, em intervalos de 45 dias, em cobertura.

Todos os tratamentos receberam uma adubação orgânica na proporção de 10 litros de esterco de curral para cada planta, aplicados em sulcos laterais, na projeção da copa acompanhando o crescimento do sistema radicular das pimenteiras. A cada dois anos de cultivo foram aplicados 500 gramas/planta de calcário dolomítico com PRNT corrigido para $100 \%$, isto para suprir as necessidades de cálcio e magnésio, pois não foi possível a realização da calagem na área total antes da instalação do experimento.

A amostragem de folhas foi efetuada no início de maio de 1987, ocasião em que as plantas apresentavam na fase de enchimento rápido dos grãos. A coleta de amostra consistiu em coletar quatro folhas recém maduras por planta útil, do terço médio da copa da pimenteira no sentido Nordeste para Sudeste.

As amostras de folha foram colocadas para secar em estufa com circulação forçada de ar com temperatura entre 60 e $65^{\circ} \mathrm{C}$ por cerca de três dias. Depois de secado, o material foi moído em moinho tipo Willey com peneira de 20 malhas e acondicionado em saquinhos de papel para análises dos teores de N, P e K. Para determinação de $\mathrm{N}$ foi feita a digestão por oxidação sulfúrica, enquanto 0 $\mathrm{P}$ e o K foi utilizada a mistura nitro-perclórica na proporção 2:1 (Malavolta et al., 1989).

$\mathrm{O} \mathrm{N}$ foi determinado pelo método microkjeldahl, o $\mathrm{P}$ por colorimetria de molibdato-vanadato, o $\mathrm{K}$ por fotometria de chama, segundo metodologia descrita por Sarruge \& Haag (1974).

Os dados obtidos durante duas colheitas foram submetidos à análise estatística utilizando-se o programa estatístico SAS (Statistical Analysis System). Efetuou-se análise de regressão para a rendimento de grãos de pimenta do reino preta, em função das doses de $\mathrm{N}, \mathrm{P}_{2} \mathrm{O}_{5}$ e $\mathrm{K}_{2} \mathrm{O}$.

TABELA 1 - Características químicas e físicas do solo da área experimental'.

\begin{tabular}{|c|c|c|c|c|c|c|c|c|c|c|c|}
\hline $\mathrm{pH}\left(\mathrm{H}_{2} \mathrm{O}\right)$ & M.O. & $\mathrm{P}$ & $\mathrm{Ca}$ & $\mathrm{Mg}$ & $\mathrm{K}$ & Al & $\mathrm{H}+\mathrm{Al}$ & Areia grossa & Areia fina & Silte & Argila \\
\hline & $\mathrm{g} \mathrm{kg}^{-1}$ & $\mathrm{mg} \mathrm{kg}^{-1}$ & \multicolumn{5}{|c|}{ 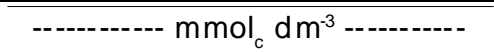 } & \multicolumn{4}{|c|}{ 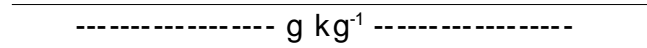 } \\
\hline 4,9 & 16,9 & 1,3 & 5,0 & 2,0 & 1,5 & 19,0 & 54,0 & 120,0 & 530,0 & 100,0 & 250,0 \\
\hline
\end{tabular}

${ }^{1}$ Análises realizadas no Laboratório de Solos da Embrapa Amazônia Oriental. 


\section{RESULTADOS E DISCUSSÃO}

Os dados de produção de pimenta-do-reino são apresentados na Figura 1. Pelo rendimento obtido, observa-se que dentre as cultivares estudadas, a Guajarina apresentou, em termos médios, os melhores rendimentos em todos os tratamentos com aplicação de fertilizantes contendo N, P e K. Verifica-se, que a cultivar Cingapura apresenta o segundo melhor rendimento em produção de pimenta preta, em todos os tratamentos aplicados. Os baixos resultados de produção da cultivar Bragantina podem ter sido influenciados pela ocorrência de fusariose, de vez que, dentre as cultivares, foi a mais infectada pelo fungo, ao final do experimento.

De acordo com a análise de regressão dos resultados de produção de pimenta preta das três cultivares estudadas, para os efeitos isolados de doses de nitrogênio (Figura 2.), observa-se que a equação quadrática é a que melhor explica os resultados obtidos, para os respectivos nutrientes em função das dosagens utilizadas em cada da cultivar.

Conforme estes resultados, verifica-se respostas bastante acentuadas da cultivar Guajarina, para todos os nutrientes aplicados, via adubação mineral, principalmente para o nitrogênio. De modo geral, verificou-se que as cultivares Cingapura e Bragantina apresentaram um padrão de produção bastante semelhante, para as diferentes doses aplicadas. Pode-se inferir ainda, que a aplicação de doses crescentes de nitrogênio favoreceu a obtenção de melhores respostas para todas as cultivares estudadas.

A nutrição nitrogenada adequada, segundo Malavolta (1984) não havendo outros fatores limitantes, é evidenciada no desenvolvimento rápido, no aumento da ramificação dos galhos frutíferos e na formação de folhas verdes e brilhantes. Por outro lado Raij (1981) e Kiehl (1985) observaram que, a utilização agrícola de um solo, promove uma queda exponencial do teor de matéria orgânica, mais rápida no início e em proporção cada vez

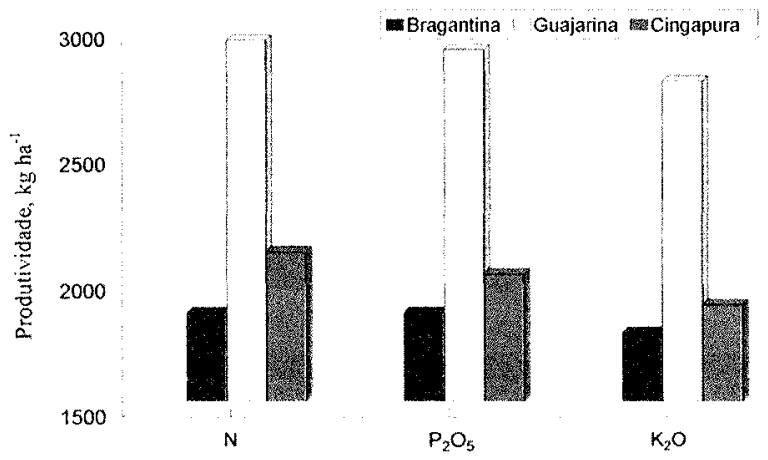

Figura 1 - Rendimento de grãos de três cultivares de pimenta-doreino, em resposta a doses crescentes de nitrogênio, fósforo e potássio, aos 29 meses após o plantio. menor, buscando um novo equilíbrio. O suprimento de nitrogênio decresce em consequência deste fenômeno, sendo em geral insuficiente para as culturas. De acordo com Sanchez (1981), além da fixação biológica, um aporte importante de $\mathrm{N}$ em solos tropicais é devido às chuvas, podendo ser superior a $10 \mathrm{~kg}$ de N/ha. Segundo este autor, nas regiões com estação seca definida (caso da microrregião de Altamira), pode haver acumulação de nitratos neste período, explicada pela nitrificação.

Em Sarawak, na Malásia Raj (1973), estudou as diferentes respostas da pimenteira, num ensaio fatorial $3^{3} \mathrm{NPK}$ em dois tipos de solos e concluiu que, altos níveis de $\mathrm{N}$ e $\mathrm{K}$ proporcionaram os maiores aumentos de produção.

No que diz respeito a fósforo, observa-se na Figura 3 que as equações de regressão entre doses de $\mathrm{P}_{2} \mathrm{O}_{5}$ e a produção de grãos de pimenta do reino preta foram significativas nas colheitas obtidas aos 17 e 29 meses de cultivo em todas as cultivares utilizadas, sendo que as quantidades de $\mathrm{P}_{2} \mathrm{O}_{5}$ aplicadas, correspondentes à produções máximas, aumentaram com os meses devido ao crescimento da planta, e o aumento de sua capacidade
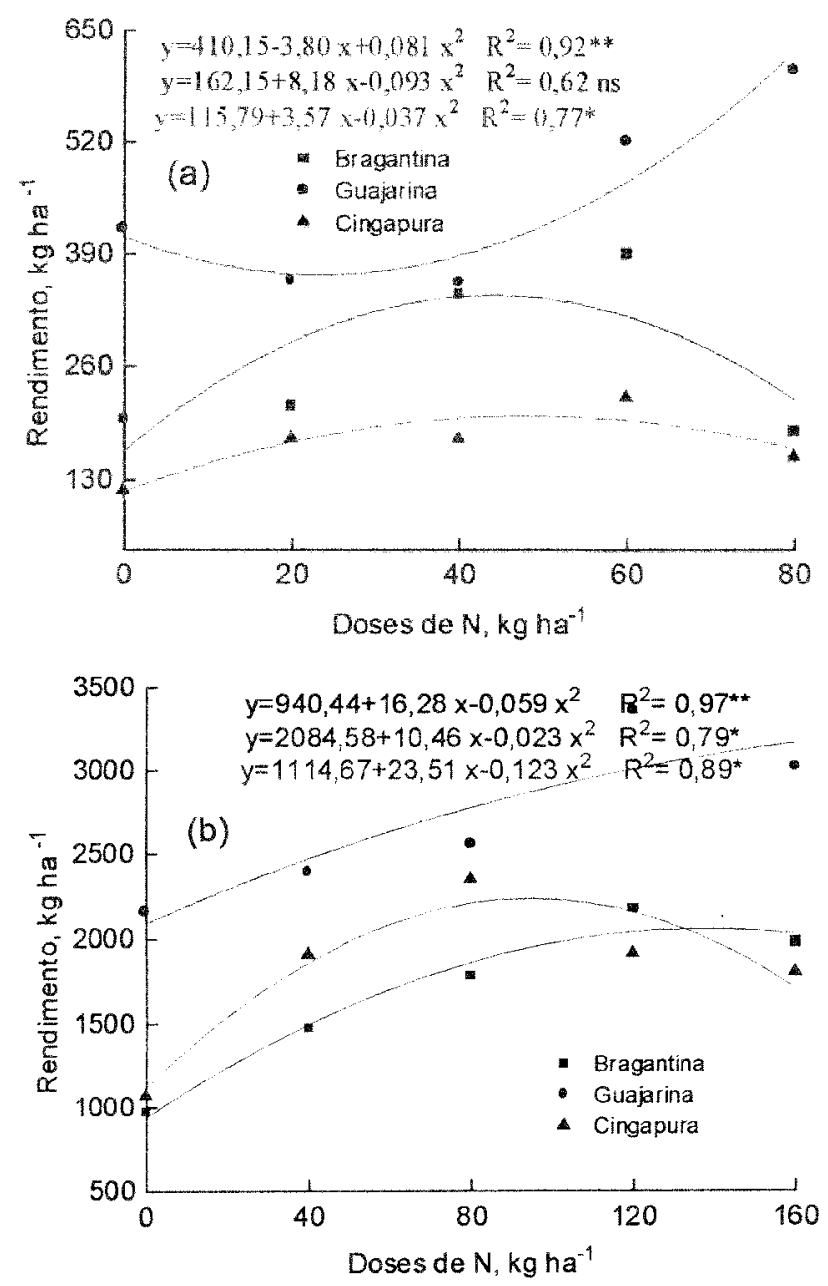

Figura 2 - Efeito de doses de nitrogênio sôbre o rendimento de grãos de cultivares de pimenta-do-reino aos 17 mêses (a) e aos 29 mêses (b) de cultivo. 
produtiva e à produção. Também no Estado do Pará Albuquerque \& Condurú (1971) realizaram um ensaio de adubação e obtiveram significativas respostas à adubação NPK, principalmente quando associados à matéria orgãnica. No caso de solos de fertilidade muito baixa e já utilizados anteriormente com outras culturas, esses autores evidenciam a grande importância de determinados tratos culturais, como a aplicação de cobertura morta e o enterrio de matéria orgânica.

Os efeitos de doses de $\mathrm{K}$ aplicadas sobre a produção de grãos de pimenta do reino preta são apresentadas na Figura 4, observa-se que houve resposta quadrática quando se utilizaram os dados das colheitas obtidas aos 17 e aos 29 meses de cultivo. Observa-se que aos 17 meses ocorre rendimentos decrescentes para o cultivar Cingapura, demonstrando também aos 29 meses pequena resposta para as doses de $\mathrm{K}_{2} \mathrm{O}$ utilizadas. Quanto as demais cultivares houve melhor resposta de potássio para a Guajarina e Bragantina demonstrando maior eficiência na utilização de adubos minerais.
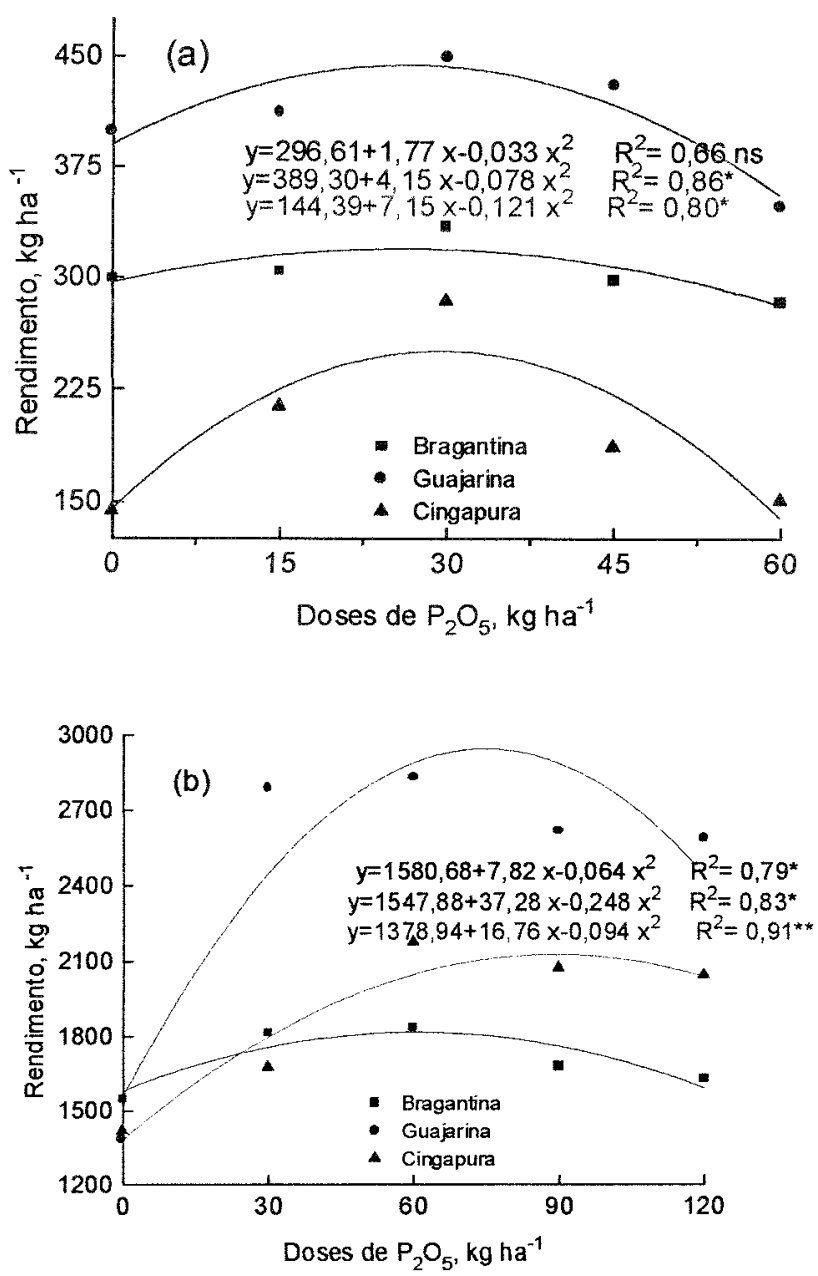

Figura 3 - Efeito de doses de fósforo sôbre o rendimento de grãos de cultivares de pimenta-do-reino aos 17 mêses (a) e aos 29 mêses (b) de cultivo.
Levando-se em conta que a produção ótima seria atingida com $90 \%$ da máxima produção das cultivares testadas, a análise de regressão possibilitou estimar que os melhores resultados foram obtidos com a aplicação de 72 e $78 \mathrm{~kg} \mathrm{ha}^{-1}$ de nitrogênio, para as cultivares Cingapura e Bragantina, respectivamente; de 47 $\mathrm{kg} \mathrm{ha}^{-1}$ de $\mathrm{P}_{2} \mathrm{O}_{5}$, para a cultivar Guajarina; e de 42, $13 \mathrm{e}$ $22 \mathrm{~kg} \mathrm{ha}^{-1}$ de $\mathrm{K}_{2} \mathrm{O}$, com produtividade média de pimenta preta em torno de 2700,2300 e $3850 \mathrm{~kg} \mathrm{ha}^{-1}$, para as cultivares Cingapura, Bragantina e Guajarina, respectivamente.

Com relação aos teores de nitrogênio, fósforo e potássio encontrados no tecido foliar, as cultivares Bragantina, Cingapura e Guajarina (TABELA 2), revelaram que a adubação nitrogenada foi adequada, encontrandose dentro da faixa ótima de nutrição da pimenteira, ou seja 31 a $34 \mathrm{~g} \mathrm{~kg}^{-1}$ de N indicada por Waard (1969).

A adubação fosfatada proporcionou comportamento semelhante nas cultivares estudadas, onde também foram encontrados teores dentro da faixa ótima considerada por Waard (1969); 1,6 a $1,8 \mathrm{~g} \mathrm{~kg}^{-1}$ de $P$.
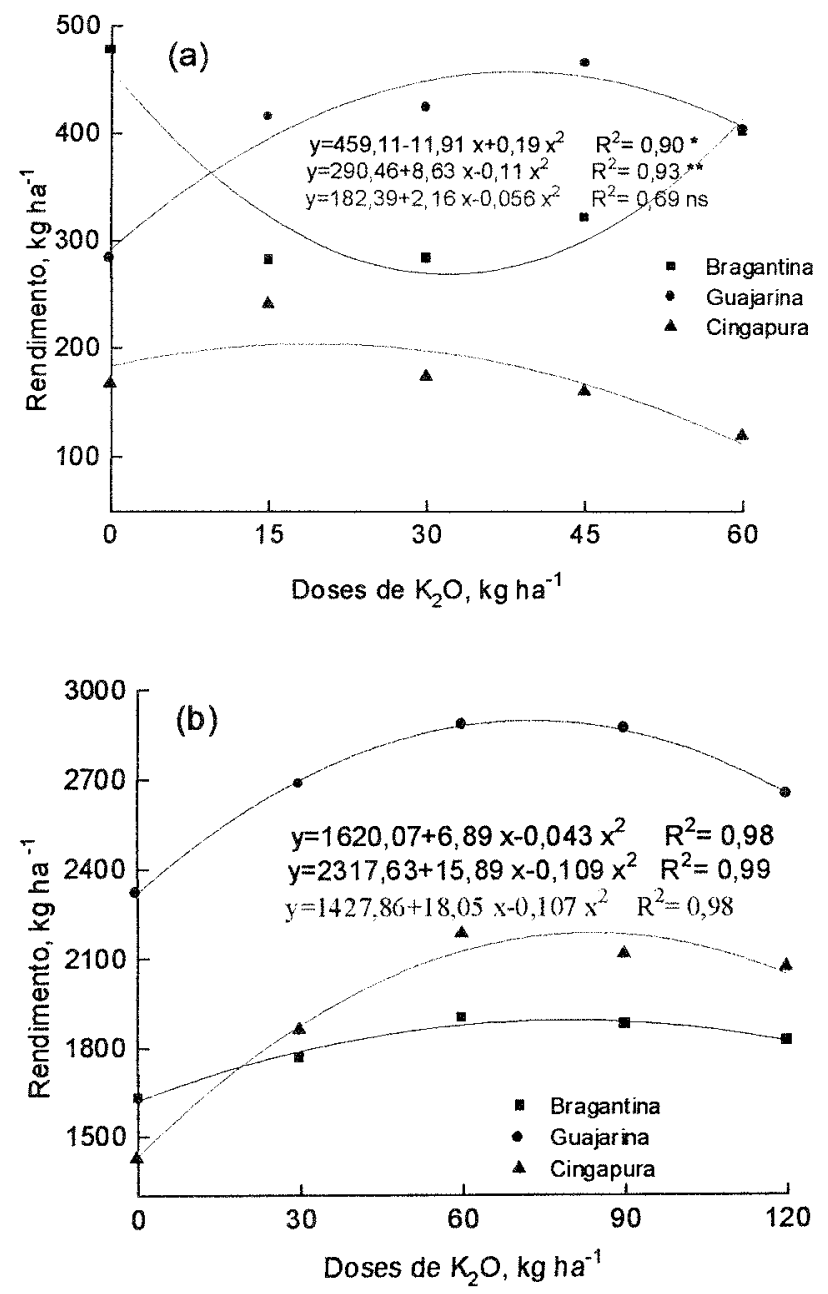

Figura 4 - Efeito de doses de potássio sôbre o rendimento de grãos de cultivares de pimenta-do-reino aos 17 mêses (a) e aos 29 mêses (b) de cultivo. 
TABELA 2 - Teores médios de N, P e K nas folhas das cultivares de pimenta-do-reino, aos 29 meses de idade nos diferentes tratamentos (1).

\begin{tabular}{|c|c|c|c|c|c|c|c|c|c|}
\hline \multirow{3}{*}{ Tratamentos } & \multicolumn{9}{|c|}{ Cultivares } \\
\hline & \multicolumn{3}{|c|}{ Bragantina } & \multicolumn{3}{|c|}{ Cingapura } & \multicolumn{3}{|c|}{ Guajarina } \\
\hline & $\mathrm{N}$ & $\mathrm{P}$ & $\mathrm{K}$ & $\mathrm{N}$ & $\mathrm{P}$ & $\mathrm{K}$ & $\mathrm{N}$ & $\mathrm{P}$ & $\mathrm{K}$ \\
\hline & & & & & $y^{-1}-$ & & & & \\
\hline 111 & 45,5 & 8,9 & 20,0 & 32,5 & 6,4 & 22,0 & 30,8 & 4,8 & 20,0 \\
\hline 311 & 49,7 & 7,4 & 19,0 & 39,2 & 5,4 & 18,0 & 34,7 & 4,1 & 16,0 \\
\hline 131 & 47,9 & 7,4 & 22,0 & 38,1 & 6,2 & 21,0 & 39,8 & 5,6 & 20,0 \\
\hline 331 & 45,1 & 6,4 & 21,0 & 39,8 & 5,9 & 20,0 & 37,0 & 4,2 & 19,0 \\
\hline 113 & 47,6 & 7,1 & 20,0 & 37,5 & 5,6 & 24,0 & 38,1 & 4,9 & 24,0 \\
\hline 313 & 46,9 & 6,3 & 20,0 & 38,6 & 4,9 & 20,0 & 38,6 & 4,0 & 20,0 \\
\hline 133 & 47,9 & 7,3 & 22,0 & 40,9 & 8,5 & 23,0 & 34,7 & 4,9 & 23,0 \\
\hline 333 & 45,8 & 5,8 & 21,0 & 38,1 & 5,4 & 21,0 & 37,5 & 4,5 & 23,0 \\
\hline 022 & 44,8 & 6,7 & 20,0 & 38,6 & 5,9 & 22,0 & 35,3 & 5,2 & 22,0 \\
\hline 422 & 45,1 & 6,5 & 19,0 & 41,8 & 5,6 & 21,0 & 35,3 & 4,5 & 19,0 \\
\hline 202 & 50,0 & 6,0 & 20,0 & 39,8 & 4,8 & 21,0 & 38,1 & 4,1 & 22,0 \\
\hline 242 & 50,7 & 7,7 & 20,0 & 43,1 & 5,8 & 20,0 & 35,3 & 5,1 & 20,0 \\
\hline 220 & 46,5 & 6,5 & 18,0 & 40,9 & 6,3 & 20,0 & 35,8 & 4,7 & 16,0 \\
\hline 224 & 44,4 & 8,1 & 21,0 & 43,1 & 6,2 & 23,0 & 32,5 & 4,6 & 20,0 \\
\hline 222 & 50,4 & 7,0 & 21,0 & 39,8 & 6,3 & 21,0 & 30,2 & 4,2 & 18,0 \\
\hline
\end{tabular}

${ }^{1}$ Análises realizadas no Laboratório de Solos da Embrapa Amazônia Oriental.

\section{CONCLUSÕES}

- Há resposta positiva de nitrogênio com relação a produção de grãos de pimenta do reino com a aplicação de 72 e $78 \mathrm{~kg} \mathrm{ha}^{-1}$ de N, para as cultivares Cingapura e Bragantina, respectivamente.

- Somente a cultivar Guajarina, respondeu à aplicação de fósforo.

- Doses crescentes de $\mathrm{K}_{2} \mathrm{O}$, reduziu os teores de potássio presentes no tecido foliar das pimenteiras.

- A adição de potássio favoreceu o aumento da produção de grãos com a aplicação de 42, 13 e $22 \mathrm{~kg} \mathrm{ha}^{-1}$ de $\mathrm{K}_{2} \mathrm{O}$, para as cultivares Cingapura, Bragantina e Guajarina, respectivamente.

\section{REFERÊNCIAS BIBLIOGRÁFICAS}

ALBUQUERQUE, F.C. de; CONDURU, J.M.P. Cultura da pimenta do reino na região amazônica. Belém: IPEAN, 1971. 149p. (Série Fitotecnia, v.2).

ANUÁRIO ESTATÍSTICO DO BRASIL - 1996. Rio de Janeiro, v.56, p.3-55, 1997

COCHRAN, W.G.; COX, G.M. Experimental designs. 2.ed. New York: John Wiley, 1957.611p.

CHIBA, M.; TERADA, S. On the optimum amount of fertilizer based upon the amount of nutrients absorbed by pepper plant in Amazonia Region. Japanese Journal of Tropical Agriculture, v.20, p.14-21, 1976.

FALESI, I.C. O estado atual dos conhecimentos sobre os solos da Amazônia Brasileira. In: INSTITUTO DE PESQUISA E EXPERIMENTAÇÃO AGROPECUÁRIA DO NORTE. Zoneamento agrícola da Amazônia. Belém: IPEAN, 1972. p.17-67. (Boletim Técnico, 54).

KATO, A.K. Teor e distribuição de N, P, K, Ca e Mg em pimenteiras do reino (Piper nigrum, L.). Piracicaba, 1978. 75p. Dissertação (Mestrado) - Escola Superior de Agricultura "Luiz de Queiroz", Universidade de São Paulo.

KIEHL, E.J. Fertilizantes orgânicos. São Paulo: Agronômica Ceres, 1985. 492p.
MAISTRE, J. Las pimientas. In: MAISTRE, J. Las plantas de especias. Barcelona: Ed. Blume, 1969. p.123-208.

MALAVOLTA, E. Nutrição, adubação e calagem para o cafeeiro. In: RENA, A. B. (Coord.) Simpósio sobre fatores que afetam a produtividade do cafeeiro. Poços de Caldas, 1984. v.2, p.88-226.

MALAVOLTA, E.; VITTI, G.C.; OLIVEIRA, S.A. Avaliação do estado nutricional das plantas; princípios e aplicações. Piracicaba: Potafós, 1989. 201p.

MORAES, V.H.F. Ocorrência de deficiência de magnésio em pimenta do reino (Piper nigrum, L.) em condições de campo. Pesquisa Agropecuária Brasileira, v.3, p.147-149, 1968.

RAIJ, B. van Avaliação da fertilidade do solo. Piracicaba: Instituto da Potassa e Fosfato, 1981. 142p.

RAJ, H.G. Response of black pepper (Piper nigrum, L.) to inorganic fertilizers in Sarawak, Malaysia. Malaysian Agricultural Journal, v.49, p.66-73, 1973.

SANCHEZ, P.A. Suelos del tropico: características y manejo. San Jose: IICA, 1981. 660p. (Série de libros y materiales educativos, 48).

SARRUGE, J.R.; HAAG, H.P. Análise química em plantas Piracicaba: ESALQ/USP, 1974. 56p.

SIM, E.S. Dry matter production and major nutrient contents of black pepper (Piper nigrum, L.) in Sarawak. Malaysian Agricultural Journal, v.48, p.73-93, 1971.

VELOSO, C.A.C.; MURAOKA, T.; MALAVOLTA, E.; CARVALHO, J.G. Efeitos do alumínio em pimenteiras do reino (Piper nigrum, L.) cultivadas em solução nutritiva. Scientia Agricola, v.52, p.368-375, 1995

WAARD, P.W.F. Pepper cultivation in Sarawak. World Crops, v.16, p.24-30, 1964.

WAARD, P.W.F. Foliar diagnosis, nutrition and yield stability of black pepper (Piper nigrum, L.) in Sarawak. Amsterdam: Royal Tropical Institute, 1969. 149p. (Communication, 58).

WAARD, P.W.F. Problem areas and prospects of production of pepper (Piper nigrum, L.); an overview. Amsterdam: Royal Tropical Institute, Department of Agricultural Research, 1980. 29p. (Bulletin, 308)

Recebido em 18.09.99 